\title{
An Online Student-Oriented Assessment Program for the Core Subjects of Bachelor and Master Studies in Technical Higher Education
}

\author{
Brânduşa Prepeliţă Răileanu \\ University - Politehnica" of Bucharest \\ Faculty of Engineering in Foreign Languages \\ Splaiul Independenţei 313, Ro-060032 \\ Bucharest, Romania
}

\begin{abstract}
The paper emphasizes positive experience in the use of Information and Communication Technology in education and training programs. It is shown that ICT has helped improve the scope, quality and effectiveness of these programs. The initiatives of the University Politehnica of Bucharest in this domain have enabled users of ICT to focus on the precise learning needs and abilities of the students. Furthermore, ICT has improved efficiency in the monitoring and overall management of the training process. The paper evolves the idea according to which the benefits already gained in industry can also be achieved in the public education sector, provided that the necessary investment in technical facilities and related training is made.
\end{abstract}

Keywords - core subjects, assessment program, mathematics, physics, labour market, handbook, software tools, databases, methodology, assessment modules.

\section{INTRODUCTION}

In today's society, students and teachers are, on one hand, confronted with an ever growing load of information and content and, on the other, with increasing demands for knowledge and skills. To cope with this, it is necessary to link content, knowledge and learning, making content and knowledge more accessible, interactive and usable over time by humans and machines alike [1].

The educational goal of Romanian teachers is to create a broader community of scholars, students, and practitioners. A community that gives all members, irrespective of location and position, an equal opportunity to participate in creating and sharing information. We need a healthy, stimulating academy that embraces fresh ideas, different perspectives, and divergent experiences [2]. We must plan consciously how to use information technology to overcome the shortcomings of the present system so as to permit greater participation by those who have previously been on the extremity. Such an initiative will be presented in this paper. It belongs to the University Politehnica of Bucharest and it refers to the use of the Internet to train students in the domains of Mathematics and Physics. Finally were introduced in this project Informatics, Chemistry and Mechanical Engineering in the framework of the POSDRU Project/86/1.2/S/62485 - 'An Online Student-Oriented Assessment Program for the Core Subjects of Bachelor Studies and Master from the Technical Higher Education' directors of Grant: PhD. professor engineer Marian Gheorghe and $\mathrm{PhD}$. professor engineer Nicolae Ţăpuş, pro-rectors of the University Politehnica of Bucharest. The beneficiaries and partners of this project are, besides the University Politehnica of Bucharest, the Technical University of Cluj Napoca, the Technical University Gheorghe Asachi' of Iassy and the University of Craiova. The project is co-financed by European Social Fund.

\section{A TRAINING AND ASSESSMENT PROGRAM}

The general aim of this project is to create and to implement a training and assessment program for students and teaching staff that interact at core subjects such as mathematics, physics etc. for bachelor and master studies, from the technical higher education, at a multi-regional level regarding professional, functional and quality teaching requirements. The necessities of the labour market, the development of science and technology, the progress of economy and of the society based on knowledge are taken into consideration being applied in the medium and long term during the project and continuously afterwards.

The specific aims of the project are:

- the approach of the core subjects and of the related data bases, through groups of modules focused on analytical programs, bibliographies, courses, seminars, virtual laboratory works, case studies, optimal solutions etc.

- the definition and the achievement of training and assessment activities: documentation, teaching, 
testing etc., as student-oriented activities which are classified into modules which should contribute to the development of skills/competences of students in an interactive, amiable and fast way;

- the conceiving, achievement and testing of the online operation system at a multi-regional level;

- the formation, assessment and attestation of the teachers' ${ }^{\text {' and system administrators }}{ }^{\text {' competences; }}$

- the training and the assessment of the skills/competences of students in the process of training and assessment through complex training and assessment modules achieved.

The project will produce positive effects in the long term and at a multi-regional level because the training and assessment activities will be student-oriented and will be developed online during the Grant and afterwards within different academic partnerships.

In the preliminary phase of this program the team was made of professors from the staff of the Faculty of Applied Sciences who participated at a first stage of the program which was initially designed for the subjects: Mathematics and Physics. The Faculty of Applied Sciences was established in 2005 (the International U.N.O., U.N.E.S.C.O. and World Year of Physics, and the year of implementation of the European Higher Education Reform in Romania). It includes the Departments of Mathematics and Physics and the curricula they have been offered in U.P.B. for all three academic cycles: Bachelor, Master and Doctoral ones and their offer of basic education in Mathematics and Physics to all U.P.B. students.

The present curricula have been offered: since 1955 Engineering Physics - within the Faculty of Electronics and since 1991 - Engineering Mathematics - within the Faculty of Electrical Engineering. They have continuously been improved.

Starting with 1994 Advanced Study Programs have been offered in Technical Physics, Photonics, Optical Technologies, Dynamical Systems, Differential Geometry and Optimization, Models in Decision Theory, Risk and Forecasting.

Professors of the Departments of Mathematics and Physics have been doctoral supervisors of doctoral curricula offered by U.P.B. and by some Romanian Academy Research Institutes. Since 1998 the Department of Mathematics and Physics has been established to offer doctoral curricula in the field of Exact Sciences: Mathematics and Physics.

In order to highlight the extent of the initiative to which we refer to, some major research domains are mentioned such as:

- In Mathematics - analytical and numerical methods in boundary value differential equations problems, probabilistic models in reliability studies, stochastic phenomena statistics, applied functional analysis, fractal theory, optimization, perturbations and asymptotic analysis, biometrics, complex analysis in technical applications, differential geometry, geometrical dynamics modelling, statistical analysis of experimental data, nonlinear dynamics and chaos, mathematical economics, systems and control theory;
- In Physics - optoelectronics, laser and plasma, superconductivity, interaction laser - substance, scanning laser confocal microscopy, atomic force microscopy, magnetism, condensed state physics, liquid crystals, holography, hologram interferometry, optical processing of information, holographic manufacturing, holographic techniques in visual arts, physical models in social and human sciences.

There are three Research Centres as part of the Faculty of Applied Sciences:

- FOCUM (Academic Centre for Optical Engineering and Photonics)

- CCSFA (Scientific Research Centre in Applied Physics")

- CMMPI (Centre for Microscopy - Microanalysis and Information Processing) Laser scanning confocal microscope (Centre for Microscopy - Microanalysis and Information Processing)

Also in the Faculty of Applied Sciences the following international reviews are being edited:

- Series A - Mathematics and Physics - Scientific Bulletin of University POLITEHNICA of Bucharest (hard issue)

- Balkan Journal of Geometry and Its Applications (hard and electronic issue)

- Applied Sciences (electronic issue)

- Differential Geometry \& Dynamical Systems (electronic issue)

- BSG Proceedings (hard and electronic issue)

Starting from the idea that many students learn best working together on structured, self-directed projects, the mathematicians from the Faculty of Applied Sciences have created software that links students and other social software tools to a virtual collaborative learning environment.

The researchers of the Faculty of Applied Sciences (University Politehnica of Bucharest) wanted to create software tools that would let university students and teachers work together on structured, self-directed learning projects regarding both their training for entrance to the University and later the specialized training in the domains of Mathematics and Physics. The project offered the opportunity to use the Internet to collaborate with students outside regional boundaries. Using the Internet, a group of students could simultaneously learn the same subjects. A virtual research team could rapidly exchange findings and insights and collectively advance knowledge on a large frontier. The Internet was ideal for coordinating such a study. Professors and the future students from the Faculty of Applied Sciences set out to close the gap between existing educational software tools - usually rigidly structured and teacher-controlled - and the free-wheeling, self-directed social software that students used in their spare time, such as blogs, messaging, feeds and other social networking services.

The promoters of this project believed that students gained new knowledge and skills most readily by working together with others on projects that they themselves define and manage, facilitated rather than controlled by teachers. This training project prepared them to be more self directed, teamwork oriented, and technologically adapted later in life. 
Because students need to be competent in self direction, social networking and collaboration in technologically mediated environments.

The project was initiated by a team of professors of Mathematics and Physics from the Faculty of Applied Sciences of the University Politehnica of Bucharest for the training of the entrance examination. In a first phase, a structure of the project was established in collaboration with members of McGraw Hill staff. The project was online. The students had access to the database of the project and they were able to learn both individually and under the supervision of the teaching staff, with feedback from the computer and/or from the professors.

In the University Politehnica of Bucharest, Calculus was applied to a pilot course in Mathematics. It was common to fifteen faculties of the University Politehnica of Bucharest and it was extended to the courses of Mathematics and Physics of the first and second academic years.

The objectives of the first phase of the project were:

General objectives:

- $\quad$ to establish a hierarchy of the students according to their level of knowledge using a wide range of subjects and problems

- $\quad$ to ensure the admission of examination candidates with considerable knowledge and chances of development

- to operate a selection and an elimination of those candidates who were not well prepared.

Specific objectives:

- as the result of the examination to establish for each admitted candidate the gaps in his/her knowledge

- $\quad$ elaboration of ILP (Internal Learning Path)

The Body of Knowledge (BOK) contained the part of the syllabus which was the same for all faculties, needed by the internal logic of the discipline. It was made of ILO (Individual Learning Objects - sections of the curricula on distinct subjects)

The curriculum was divided into these sections, each containing theoretical presentations, commentaries, proposed problems, sample problems solved, applications, indications of the prerequisites of the sections, presentations of materials, self-graded homework.

Periodically tests were given. Their purpose was to highlight possible deficiencies in the students ${ }^{6}$ knowledge and to indicate extra ILOs necessary to the elimination of these deficiencies.

So ILPs (Internal Learning Path) had dynamic and flexible characteristics.

Also, the same ILOs (Individual Learning Objects) contained bonus materials for more advanced students, designed:

- $\quad$ to complete superior preparation with the purpose of participating in mathematical contests at different levels:

- Local (University Politehnica of Bucharest)

- National

- Balkan region

- European Union

- $\quad$ to elaborate papers on Applied mathematics for Students

Communications Sessions organized
- Locally (in University Politehnica of Bucharest)

- Nationally (with students from technical, mathematical and computer science faculties in Romania)

- In cooperation with faculties abroad

Besides BOK (Body of Knowledge, which was common to all the faculties), the second part of the body of the project was Math Zone by Faculties.

This part contained chapters on mathematics with applications which were specific to technical curricula for each type of faculty (Electrical faculties, Mechanical faculties, Chemical faculties, Applied Sciences faculties)

It had a content similar to ILP except for a more focused approach to applications.

Quizzes and Midterms were included into the system to cover theory and applications.

Students " preparation in ILP and in Math Zone was done in the final examination which had the following features:

-universal final for all students

-both theoretical and application based testing

-algorithmically generated questions

-self-graded with linkage to BOK (Body of Knowledge) and MZ (Math Zone)

If the candidate failed, depending on the deficiencies indicated by the students' answers, a new ILP (Internal Learning Path) to redo the students' average was generated algorithmically.

The project would have created next-generation support and advice services to enhance individual and collaborative building of competences and knowledge creation in educational and organizational settings. The project made extensive use of language technologies and cognitive models in the services.

The learning activities were enveloped by activities that ensured common ground in use cases and pedagogically sound scenarios that steered the design and development of the processes and guided the validation.

The research in the project was organized in 3 themes, each leading to particular types of services and infrastructures:

- services were developed to establish the current position of the learner in a domain. Services would have offered semi-automatic analysis and comparison of learner portfolios to the domain knowledge and continuous modelling and measurement of conceptual development.

- $\quad$ support and feedback services were developed based on the analysis of the interactions of students - using Natural Language Processing (NLP) and Social Network Analysis (SNA) and textual output of students - using Latent Semantic Analysis with contributions from NLP.

- a knowledge sharing infrastructure was construed that allowed comparison and sharing of private knowledge to give rise to new common knowledge and social learning. 
The services were expected to result in improved appreciation of learner requirements, leading to better recommendations on study plans and resources. Progress monitoring based on learning activities, rather than on formal assessments, would have improved recommendations for further competence building and improved co-construction of knowledge in social and informal learning.

With regard to the technological advancements the main focus in this project was set on social software technologies and its usage and adaptations for specific educational needs. A set of tools, including ready to use elements, up to rather experimental technologies that needed further research before they could be implemented in practice, were developed. The project team committed itself to an open source policy and published all code developed during the project under creative common licence at McGraw-Hill. Finally, from the practical experience of applying innovative pedagogical intervention strategies in combination with social software technologies, a handbook would have been derived, a handbook which was mainly targeting educational practitioners in higher education. One of the main strengths of the project was definitely the large fieldwork that would have been performed.

\section{NEW LEARNING ENVIRONMENTS}

At the beginning of this paper, I mentioned a new and much bigger project which brought together a much larger number of professors from the University Politehnica of Bucharest, the Technical University of Cluj - Napoca, the Technical University Gheorghe Asachi' of Iassy and the University of Craiova in the framework of the POSDRU Project/86/1.2/S/62485 - 'An Online Student-Oriented Assessment Program for the Core Subjects of Bachelor Studies and Master from the Technical Higher Education' (directors of Grant: PhD. Prof. Eng. Marian Gheorghe and PhD. Prof. Eng. Nicolae Ţăpuş).

I should specify the extent of the domains of education and research that the students of the Faculty of Applied Sciences have the advantage of competitive and creative environment (mathematics, physics, management, student research teams and sport contests), free access to all UPB facilities and to a system of national and international grants of mobility for study and research, including, through European Union Socrates Program, Bilateral Agreements with the following institutions: Êcole Polytechnique in Paris and I.N.P. in Grenoble (supplemented by Double Diplome agreements); Politechniques in: Stockholm, Milan, Torino, Helsinki, Tampere, Mikkeli, Lisbon, Darmstadt; Universities in: Heidelberg, Berlin, Copenhagen (Niels Bohr Institute), Uppsala, Barcelona, Madrid, Lisbon, Rome, Genova, Torino, Brescia, Gand, Paris VI, Lyon 1, Grenoble 1, Versailles, Siegen, Compiegne, Messina, Thessaloniki, Munchen. Through the agreements „European Mobility Scheme for Physics Students" all about 200 academic partners recognize the Applied Sciences Diplomas and Certificates granted by UPB.
The Project which I referred to is designed to evolve practical methodology, approaches and tools targeted at dayto-day utilization by the teacher trainers and students.

The activities performed within this project, focused on the $1-3$ academic years, are:

- The development of core subjects / modules.

- The development of training and assessing activities.

- The establishing of databases.

- The development of the online system.

- The devising and implementation of methodology / of the system / of complex training and assessment modules.

- The management of the project.

- Informative and advertising activities.

- The training, achievement and completing of public acquisitions.

- $\quad$ The closing and final spreading of the results.

Several important actions have been performed:

$>$ The formation and testing of databases.

$>$ The determination of features, the formation and testing of online operating sytem.

$>$ The testing and the completion of methodology / system / complex modules of training and assessment.

$>$ The training, assessment and testing of the quality of trainer - assessor and system administrator.

$>$ The training and assessment of the specific skills of the students from the target group.

$>$ The organization of contests of subjects for the students from the target group.

$>$ Conferences for launching and closing of the project.

$>$ Seminars for presenting the project.

$>$ The achievement and updating of a web page designed for the project.

$>$ The elaboration, the multiplication and the spreading of a booklet designed for the project.

$>$ The closing and the final spreading of the results.

The results of the project which are correlated with the activities of the project, with the indicators of instant achievement (output) and with result indicators, materialized in figures are as follows:

1. Five categories of core subjects and related databases / modules developed within the project.

2. Three hundreds of teachers and persons from the ancillary staff that have participated in the development of core subjects and related databases within the project.

3. Seventy teachers and persons from the ancillary staff that have participated in activities of training and assessment within the project.

4. Thirty teachers have participated in the development of the online operating system.

5. Thirty teachers have participated in the achievement of the methodology, the system and of complex building and assessment modules focused on the objective online student. 
6. $40 \%$ is the percentage of teachers from the core subjects (from the curricula of the bachelor and master studies), teachers who have achieved the development of complex building and assessment modules focused on the online student.

7. 130 members of leadership structures, of committees for quality assurance in the partner universities as well as of the councils, committees and other structures at the national level have participated in activities of information and development of quality requirements regarding methodology and the system of building and assessment of core subjects.

8. 200 teachers have benefitted from the building and assessment activities in the project through which they have received the quality of being builderassessor or system administrator.

9. 4.500 students have benefitted from training through building and assessment modules achieved in the project

10. 45 curricula of bachelor and master studies from the technical higher education have benefited from the system of building and assessment modules which have been achieved within the project and which have been implemented in the partner universities.

11. $40 \%$ is the percentage of the students who study the core subjects from the curricula of bachelor and master studies and who have benefitted from training and assessment through the methodology, the building and the assessment system which have been achieved within the project.
12. The quality level of training students in the core subjects from the curricula of Bachelor studies is $25 \%$ bigger than the quality level of training students in the present classic system.

13. The development level of core subjects from the curricula of Bachelor studies in this project has risen with $25 \%$ comparatively with the present level of the subjects.

14. The number of skills / curricula of Bachelor and Master studies is 45 in the technical higher education from the universities beneficiary of the methodology, of the system and of complex modules of training and assessment, online student - oriented, through which students are trained in core subjects.

In the final form, the operating system is made of five modules, for the five fundamental subjects, denoted by D.

$\mathrm{D}$ is $\mathrm{M}$ for Mathematics, F for Physics, $\mathrm{C}$ for Chemistry, $\mathrm{N}$ for Mechanical Engineering and I for Informatics. Each module D is structured as a matrix with $\boldsymbol{m}$ rows and $\boldsymbol{n}+\boldsymbol{1}$ columns. Each row of the matrix is devoted to a sub-module which represents a course or a group of connected courses of the corresponding discipline. The first element of a row denoted $\mathbf{C} \boldsymbol{i}$ presents the structure of the sub-module $\boldsymbol{i}, \boldsymbol{I} \leq \boldsymbol{i} \leq \boldsymbol{m}$, i.e. the list of the parts (chapters) $\boldsymbol{C} \boldsymbol{i j}, \boldsymbol{l} \leq \boldsymbol{i} \leq \boldsymbol{m}, \boldsymbol{l} \leq \boldsymbol{j} \leq \boldsymbol{n}$, of course. The next $\boldsymbol{n}$ elements of the row $\boldsymbol{i}$ are these parts $\boldsymbol{C} \boldsymbol{i j}$. The parts $\boldsymbol{C} \boldsymbol{i j}$ are arranged in the increasing order of their complexity, by respecting the inner logic of the subject. The training level corresponding to the parts are indicated on the borders of the matrix. For instance, the module $\mathrm{M}$ of mathematics is represented by a matrix $\mathrm{D}=\mathrm{M}$ with $\mathrm{m}=8$ rows and $\mathrm{n}=16$ columns.

\begin{tabular}{|c|c|c|c|c|c|c|c|c|c|}
\hline \multirow{2}{*}{\multicolumn{8}{|c|}{$\begin{array}{c}\text { Core Subject/ D: Mathematics (M), Physics (F), } \\
\text { Chemistry (C), Mechanical Engineering (N), Informatics (I) } \\
D=\left\{C_{\tilde{i}} \| \tilde{i}=\overline{\mathbf{1}, m}, m=m\left(C_{i}\right)\right\}, C_{\tilde{i}}=\left\{C_{i j} \| j=\overline{\mathbf{1}, n}, n=n\left(C_{\tilde{i}}\right)\right\}\end{array}$}} & \multicolumn{2}{|c|}{ STUDENTS } \\
\hline & & & & & & & & \multirow{2}{*}{$\begin{array}{c}\text { LEVEL } \\
\text { OF } \\
\text { TRAINING }\end{array}$} & \multirow{2}{*}{$\begin{array}{c}\text { PROGRAMS } \\
\text { OF } \\
\text { STUDY }\end{array}$} \\
\hline D & \multicolumn{7}{|c|}{ COM P LEX I T Y } & & \\
\hline \multirow{2}{*}{$\begin{array}{l}\text { C } \\
\text { O }\end{array}$} & $\mathrm{C}_{1}$ & $\mathrm{C}_{11}$ & $\mathrm{C}_{12}$ & $\ldots$ & $\mathrm{C}_{1 \mathrm{j}}$ & $\ldots$ & C1n & \multirow[t]{2}{*}{ N1 } & \multirow{3}{*}{$\mathbf{L}$} \\
\hline & $\mathrm{C}_{2}$ & $\mathrm{C}_{21}$ & $\mathrm{C}_{22}$ & $\ldots$ & $\mathrm{C}_{2 \mathrm{j}}$ & ... & $\mathrm{C}_{2 \mathrm{n}}$ & & \\
\hline $\mathbf{P}$ & ... & ... & $\ldots$ & ... & ... & ... & ... & $\mathbf{N} 2$ & \\
\hline $\begin{array}{l}\mathbf{L} \\
\mathbf{E}\end{array}$ & $\mathrm{Ci}_{\mathrm{i}}$ & $\mathrm{C}_{\mathrm{i} 1}$ & $\mathrm{Ci}_{\mathrm{i} 2}$ & ... & $\mathrm{C}_{\mathrm{ij}}$ & ... & $\mathrm{C}_{\text {in }}$ & N3 & \multirow{3}{*}{ Ma } \\
\hline $\mathbf{X}$ & ... & $\ldots$ & ... & ... & $\ldots$ & ... & ... & $\mathbf{N 4}$ & \\
\hline $\begin{array}{l}\mathbf{I} \\
\mathbf{T} \\
\mathbf{Y}\end{array}$ & $\mathrm{Cm}$ & $\mathrm{Cm} 1$ & $\mathrm{Cm} 2$ & $\cdots$ & $\mathrm{Cmj}_{\mathrm{m}}$ & ... & $\mathrm{C}_{\mathrm{mn}}$ & N5 & \\
\hline \multirow[t]{2}{*}{ STUDENTS } & $\begin{array}{l}\text { Level of } \\
\text { Training } \\
\end{array}$ & N1 & $\mathrm{N} 2$ & N3 & $\mathrm{N}$ & 1 & & \multicolumn{2}{|c|}{ L: Bachelor } \\
\hline & $\begin{array}{l}\text { Programs } \\
\text { of Study }\end{array}$ & \multicolumn{3}{|c|}{$\mathbf{L}$} & \multicolumn{3}{|c|}{$\mathrm{Ma}$} & \multicolumn{2}{|c|}{ Ma: Master } \\
\hline
\end{tabular}


The sub-modules are C1=MA Linear Algebra, C2=MB Geometry, $\mathbf{C 3}=\mathbf{M C}$ Calculus, $\mathbf{C 4 = M D}$ Equations and Systems of Differential Equations, C5=ME Complex Functions and Integral Transforms, $\mathbf{C 6}=\mathbf{M F}$ Functional Analysis, Probabilities and Statistics, C7=MG Special Functions and Equations of Mathematical Physics, C8=MH Variational Calculus and Dynamic Systems. For example, the row $\mathbf{i}=\mathbf{5}$ has the first element $\mathbf{C 5}=\mathbf{M E}$ which includes the contents of the sub-module and the Index of terms. The following elements are C5,1=ME.01 Complex Functions, C5,2=ME.02Analytic Functions, C5,3=ME.03 Complex Integrals, C5,4=ME.04 Taylor and Laurent Series, C5,5=ME.05 Residues Theory, C5,6=ME.06 Conformal Mappings, C5,7=ME.07 Fourier Transform, C5,8=ME.08 Fourier Integral, C5,9=ME.09 Sine and Cosine Integrals, C5,10=ME.10 Discrete Fourier Transform and Fast Fourier Transform, C5,11=ME.11 Laplace Transform, C5,12=ME.12 Applications of Laplace Transform, C5,13=ME.13 Z-transform, C5,14=ME.14 Applications with Specialized Software and C5,15=ME.15 Self-assessment.

The student-user can access each element of the five modules. A complex system of links allows the student to navigate in various sub-modules or parts, in order to clarify the necessary prerequisites notions or techniques. For instance, a click on the title of a paragraph in Contents sends the student to the desired paragraph. Each part starts with a list of key words and ends with References. The parts contain definitions, theorems, algorithms, applications, solved exercises, proposed exercises, diagrams, applications media, films, etc.

The last by one part Ci14 of each sub-module $\boldsymbol{i}$ is devoted to applications with specialized software, including for instance Matlab, Maple and Mathematics. The last part Ci,15 contains tests of self-assessment. A student solves some tests with different grade of difficulty and he can compare his work with the correct solutions of the tests. The system provides the evaluation of the student's work and indicates the notions or even the parts which are not understood by the student and he is advised to repeat.

The project will follow a service-based approach i.e. the services will be integrated in existing e-learning environments and build on the results of open source projects in the area of e-learning and language technologies. This will enable professors to concentrate on their key tasks i.e. the design creation of a set of next-generation support and advice services. The services will be the result of an interdisciplinary effort bringing together researchers in the areas of language technology, mathematics and physics, technology enhanced learning and pedagogy.

New learning environments that are responsive, personalized and intuitively adaptable to the learner's and teacher's needs can motivate, engage and support the development of skills and competences [Lessig, 2002]. Conscious of this reality, we mention the necessity of a continuous ability to access, use and understand today's digital information in the future, through systems and tools for digital preservation.

\section{CONCLUSIONS}

Until better tools appear, there are opportunities for us to take advantage of existing information technology. The Internet could be used to distribute a course on how to transfer documents. An associated bulletin board could provide answers to questions from novice users. Professors could create and test a clear set of instructions for use of a standard set of tools and make these instructions and tools available to the students' community. The goal is clear - professors and researchers must harness the Internet to increase the community's capacity for collaboration.

The scholarly communicative potential of electronic networks is revolutionary. A number of surveys in the domain of the labour market identify as crucial and essential for the knowledge-based economy [Livingstone, 1999], the ICT-skills and the so-called soft skills, such as information and knowledge articulation and presentation, information search, gathering, evaluation, and effective use, project working, team working, problem solving, and skills for life-long learning. These soft skills can be considered to be an essential part of the ICT skills of every citizen and worker, and in this respect we can speak about enhanced ICT-skills.

\section{REFERENCES}

[1] Alberts, David S., Information Age Transformatio, Washington, DC, 2002. Available at http://www.dodccrp.org/files/Alberts_IAT.pdf.

[2] Boboila, Cristea, George V. Iordache, Marcela S. Boboila, An Online System for Testing and Evaluation, WSEAS Transactions on Advances in Engineering Education, Issue 1, volume 5, 2008, pp 20-28

[3] Lessig, L. The Future of Ideas: The Fate of the Commons in a Connected World, New York, Random House, 2002

[4] Livingstone, S., and Bovill, M. - Young People and New Media, An LSE Report, 1999

[5] POSDRU Project/86/1.2/S/62485 - 'An Online Student-Oriented Assessment Program for the Core Subjects of Bachelor Studies and Master from the Technical Higher Education

\section{Creative Commons Attribution License 4.0 (Attribution 4.0 International, CC BY 4.0)}

This article is published under the terms of the Creative Commons Attribution License 4.0 https://creativecommons.org/licenses/by/4.0/deed.en_US 